Canadian Studies in Population, Vol. 30(1), 2003, pp. 29-33

\title{
The Cohort Component Projection Algorithm: Technique, Model and Theory?
}

\author{
Thomas K. Burch \\ Adjunct Professor \\ University of Victoria \\ Victoria, British Columbia
}

\section{Introduction}

If a student were to ask a North American demographer where to find a detailed treatment of population projections, chances are he or she would be sent to a text on demographic 'techniques' or 'methods,' or urged to take a course on 'technical' demography. If the student were to look in a standard introductory textbook on population, or take a course on 'population problems' or on 'behavioural' or 'substantive demography' chances are he or she would be exposed to at best a cursory treatment of population projections, with reference to their use in population forecasting or prediction.

I have come to think that the sharp distinction between formal or technical demography on the one hand, and substantive or behavioural demography on the other, has been a costly error. And the relegation of the population projection algorithm, along with many other measures and models, to the category techniques, devalues them as scientific knowledge. The standard projection algorithm, of course, is a technique and a computational procedure. But when rightly viewed, it is more than that. It is a powerful substantive model of core population dynamics. At a basic level, it tells us clearly and accurately 'how populations work.' When viewed in the light of newer ideas in the philosophy of science, the population projection model is nothing less than a powerful demographic theory. 
Thomas K. Burch

The philosopher of science Ronald Giere recently has written of physics:

The problem is not with current scientific theories of the world, but with current theories... of what it is to acquire good scientific theories of the world. As is typically the case for individuals, our collective self-knowledge lags behind our collective knowledge of the world [Giere, 1999].

The same could be said of demography as a science - specifically as a distinct and autonomous science, as opposed to a branch of applied statistics concerned with the collection and descriptive treatment of demographic data. Demography knows more than demographers or others give it credit for. But scientific knowledge is encapsulated in theory. And much of our best theory is not recognised as such, buried as it is in 'techniques' and often dismissed as 'demographic accounting' or 'bookkeeping.'

Whence this faulty self-knowledge of demography? There are many reasons, most of them tied up with the intellectual history of modern demography. There has been the perverse influence of radical positivism [see Ernst Mach or Karl Pearson], intensified in the latter half of the $20^{\text {th }}$ century by the logical empiricism of Nagel, Hempel, and Popper. There has been the close association of scientific demography with government statistical agencies, an association that had signal advantages for demography, but also signal disadvantages, notably, a preoccupation with data collection, estimation, and descriptive analysis, at the expense of demographic theory.

\section{Anatole Romaniuc on Population Projections}

Closely related to this neglect of theory, has been a similar neglect of scientific methodology and the logic and epistemology of science as these apply to the study of human population. The demographic literature contains relatively few exceptions to this statement. ${ }^{1}$ In this note, I want to focus on one such exception, a paper by Anatole Romaniuc - 'Population projection as prediction, simulation and prospective analysis' [Romaniuc, 1990]. In this paper, Romaniuc transcends the restrictive methodological views of most demographers to highlight the multi-faceted character of population projection, including its role as a substantive model of population dynamics, that is, as theory.

In discussing population projection as prediction, Romaniuc is on familiar ground. When one wants to know the future population [size, age and sex structure] of the world, nation, or other well-defined population, one commonly turns to a standard demographic [cohort-component] population projection. We often quibble about the differences among a 'forecast,' a 'prediction' and a 
The Cohort Component Projection Algorithm:

Technique, Model and Theory?

'projection,' but often as not what we're really after is knowledge of some concrete future.

Romaniuc accepts the well-documented fact that population projections viewed as predictions have often turned out to be incorrect, a fact which he attributes to the inherent unpredictability of human behaviour. But these limits to the predictive abilities of projections do not disturb him, since he sees two other important roles for population projections.

One is the use of the population projection algorithm for simulation. Simulations, in his view, are 'prediction-neutral.' 'No attempt whatsoever is made to predict the future' [p.21]. Simulations are 'conditional' projections, and '...tautological in the sense of one set of parameters (input) being transformed into another set of parameters (output) that are relevant to the problem at hand' [p.21]. The focus is on using the projection algorithm to investigate interrelationships among demographic and other variables.

This use is less familiar than the predictive use of projection, but has found increasing application since the advent of computers rendered the sheer computational labour of doing a projection almost trivial. Suppose one wants to know in general how immigration can affect the age structure of a population. In particular, can changes in the number and kind of immigrants slow or even reverse population aging. The question can be answered by computer simulation of many population projections [realistic, but not necessary accurate with respect to any particular population], with varying assumptions about patterns of mortality, fertility, and migration. Using this approach, one can demonstrate fairly quickly that for the typical developed nation [e.g., Canada], no imaginable pattern of immigration can have more than a small impact on the age composition of the population, except perhaps in the very short term or unless one assumes that immigrants maintain fertility levels well-above prevailing below-replacement fertility.

One could similarly demonstrate the relative influence on age structure of mortality decline versus fertility decline, or the impact of delayed fertility [higher average age at childbearing] on population growth rates. Note that these simulations, if carried out with enough well chosen assumptions about inputs, yield firm scientific generalisations - knowledge of how specific kinds of populations work in well-defined circumstances. This is the basis of Keyfitz's claim that in demography '.. the most important relations cannot be established by direct observation...' - insight and understanding comes from models [Keyfitz, 1975, p.267].

The third use of population projection identified by Romaniuc is that of prospective analysis. He views it as a middle-ground between prediction and simulation: "If one pictures the transition from simulation to prediction on a continuum, with predictability ideally increasing in degree along that 
Thomas K. Burch

continuum, the prospective analysis would be found somewhere midway along the axis' [p.23]. The emphasis here is on working out plausible or possible futures for a specific population. 'These projections aim chiefly at unravelling demographic tendencies' [p.23]. Prospective analyses differ from predictions in that they do not seek certainty or even high probability, only plausibility. They differ from simulation in that they are future oriented, and in that they deal with a particular population rather than with general relationships.

The key requirement for a projection as prospective analysis is that it have what Romaniuc terms 'analytic credibility': 'The argument underlying the projection assumptions must be persuasive to both the professional peers of the producers and to the users' [p.23]. In other words, the whole projection process should be based on and should lead to understanding, not just mechanical forecasting or extrapolation. Understanding the processes that lead into the future is important in preparing for it [p.28].

Finally, Romaniuc argues that being able to predict future population accurately may be less important that getting analytic guidance to change the future: '...the performance [of a projection] is to be gauged not so much by the degree to which the projection predicts the future population...but rather by the extent to which it contributes to the decision-making processes that shape the future' [p.29].

\section{Towards Rethinking Demography}

Although specifically limited to a discussion of population projections, Romaniuc's paper has much wider relevance, containing as it does powerful ideas that challenge the way we view demography and other empirical social sciences. He does not quite use the word theory in this connection, but many scientists and philosophers of science would say that projection as simulation and projection as prospective analysis are in effect forms of theoretical analysis; the projection model is a theoretical model. The same could be said for many other elements of 'formal demography." ${ }^{2}$ In what Giere has termed the 'modelbased view of science,' the primary representational device is the model not the law. Models are true, says Giere, in the way that a definition is true. The empirical question is not whether they are true, but whether as models they fit some part of the real world closely enough in certain respects for a given analytic purpose [Giere, 1999].

Romaniuc's discussion of projection as prospective analysis and as simulation is a striking illustration of this general principle. In one fell swoop, he shows us that much of formal demography - often belittled as 'mere techniques' or 'human bookkeeping - is in fact theoretical knowledge of population dynamics. It is a reminder that in the hands of a master, methodological reflection stepping back from everyday work to think deeply about how that everyday 
The Cohort Component Projection Algorithm:

Technique, Model and Theory?

work is being done - can yield important insights into what a discipline has achieved and point the way to future progress.

Thomas K. Burch, Adjunct Professor, Department of Sociology, University of Victoria, Victoria, BC V8S 4V8; TKBurch@Uvic.ca.

\section{End Notes:}

1 See, for example, Keyfitz, 1975; Wunsch, 1995; McNicoll, 1992. Keyfitz felt it necessary to apologise in advance to his demographic audience for discussing 'epistemological' questions.

2 For a fuller development of these ideas, see Burch 2001. The same approach also calls into question the sharp distinction between formal and behavioural demography, since the models in both realms have essentially the same epistemological status.

\section{References:}

Burch, Thomas K. 2001. Data, models, theory and reality: the structure of demographic knowledge. Paper presented at seminar on Agent-Based Coemputational Demography, the Max Planck Institute for Demographic Research, Rostock, German, 21-23 February 2003.

Giere, Ronald N. 1999. Science Without Laws. Chicago: University of Chicago Press.

Keyfitz, Nathan. 1975. "How do we know the facts of demography?" Population and Development Review 1:267-288.

McNicoll, Geoffrey. 1992. "The agenda of population studies: a commentary and complaint," Population and Development Review 18:399-420.

Romaniuc, Anatole. 1990. Population projection as prediction, simulation and prospective analysis. Population Bulletin of the United Nations, No.29, pp.16-31.

Wunsch, Guillaume. 1995. 'God has chosen to give the easy problems to the physicists'; or why demographers need theory. Working Paper No. 179, Institut de Démographie, Université catholique de Louvain. 